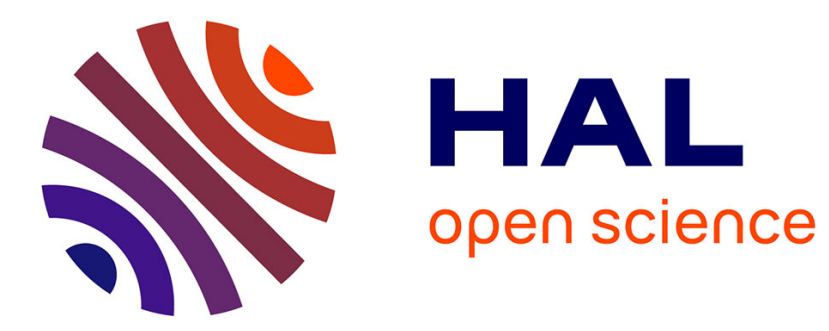

\title{
Test bench dimensioned by specific numerical tool
}

\author{
Nicolas Gascoin, Philippe Gillard, G.A Abraham, Marc Bouchez
}

\section{To cite this version:}

Nicolas Gascoin, Philippe Gillard, G.A Abraham, Marc Bouchez. Test bench dimensioned by specific numerical tool. Computer Aided Chemical Engineering, 2008, 25, pp.835-840. 10.1016/S15707946(08)80145-9 . hal-00641615

\section{HAL Id: hal-00641615 https://hal.science/hal-00641615}

Submitted on 16 Nov 2011

HAL is a multi-disciplinary open access archive for the deposit and dissemination of scientific research documents, whether they are published or not. The documents may come from teaching and research institutions in France or abroad, or from public or private research centers.
L'archive ouverte pluridisciplinaire HAL, est destinée au dépôt et à la diffusion de documents scientifiques de niveau recherche, publiés ou non, émanant des établissements d'enseignement et de recherche français ou étrangers, des laboratoires publics ou privés. 
$18^{\text {th }}$ European Symposium on Computer Aided Process Engineering - ESCAPE 18

Bertrand Braunschweig and Xavier Joulia (Editors)

(c) 2008 Elsevier B.V./Ltd. All rights reserved.

\title{
Test bench dimensioned by specific numerical tool
}

\author{
Nicolas Gascoin ${ }^{1}$, Philippe Gillard ${ }^{1}$, Gregory Abraham ${ }^{1}$, Marc Bouchez ${ }^{2}$ \\ ${ }^{1}$ LEES, 63 avenue de Lattre de Tassigny, Bourges, 18000, France \\ ${ }^{2}$ MBDA-France, 18 rue Le Brix, Bourges, 18000, France
}

\begin{abstract}
One of the main issues of hypersonic flight is the thermal management of the overall vehicle. In order to simulate the behaviour of a complete actively cooled Supersonic Combustion Ramjet, a one-dimensional transient numerical model has been developed with heat and mass transfer particularly in a cooling channel for supercritical fuel under pyrolysis. It uses a detailed pyrolysis mechanism for $n$-dodecane (1185 reactions and 153 species). A further validation of the model, based on experimental and numerical data, is presented in this paper. The hydrodynamic behaviour is considered to be good enough for this numerical tool as the accuracy of fluid velocity computation is about few percents. The model is quantitatively validated under stationary conditions for both hydrodynamic and thermal aspects. The discrepancies between computed and experimental data remain close to $5 \%$ or less on a thermal point of view. Furthermore, good agreement is found with transient experimental test case. Discrepancies are analysed and they remain in an acceptable range of a tenth of degree. A validation of the chemistry is provided thanks to experimental results. The pyrolysed mixture's compositions are well reproduced with only few percents of error. RESPIRE is now considered to be validated and it brings further analysis of the experimental data obtained with the new pyrolysis bench. Some interesting examples of use are given.
\end{abstract}

Keywords: Process Design, Multiphysic Process, Fuel Pyrolysis.

\section{Introduction}

Hypersonic flight is expected to be achieved with SCRAMJET engine. Because the total temperature of external air reaches temperatures as high as $4950 \mathrm{~K}$ for example at Mach 12, even composite materials could not withstand such large heat load. Thus, an active cooling system has to be used. Furthermore, the time allocated to the combustion in the engine is about 10-3 s. These two points lead to use the fuel to cool down the engine's wall and then to burn it in the combustion chamber. Fuel is injected in a composite channel which surrounds the engine. When heated above $800 \mathrm{~K}$, the fuel is pyrolysed and thanks to its endothermic behaviour, it ensures the active cooling of the hot walls. This pyrolysis produces lighter hydrocarbons species, which are easier to ignite. It is important to note that the expected high pressure in the cooling loop ( $>3 \mathrm{MPa}$ ) causes the fluid to become supercritical in the channel.

The principle and advantages of SCRAMJET and the interest to use hydrocarbon fuel have been fully studied (Powell et al., 2001). The modelling is a more feasible method than experiments for conducting engineering studies and for furthering research related to this topic. As both the pyrolysis and the combustion chemistry are never treated in the literature, coupled phenomena are not considered and the relationship between fuel composition and SCRAMJET thrust cannot be taken into account. The need of a specific tool considering the overall vehicle, its cooling as its thrust, is thus evident to study the entire coupled phenomena involved in the SCRAMJET's cooling. The present work falls within the framework of the COMPARER project (COntrol and Measure of 
PArameters in a REacting stReam). It aims at understanding the pyrolysis of endothermic hydrocarbon fuel under supercritical states with complementary numerical and experimental approaches. This work should help to respond to the industrial need, which is related to mass flow rate measurement and burning capacity determination.

A numerical code, called RESPIRE (a French acronym for SCRAMJET Cooling with Endothermic Fuel, Transient Reactor Programming), has been specifically developed. Its purpose is mainly to understand the relationships between the phenomena involved in the process. The aim of RESPIRE is to determine temperatures in the system to a tenth of a degree and the chemical composition at a mole fraction of $1 \%$.

An experimental test bench has also been realised to serve as a validation apparatus for RESPIRE and also as a comprehension tool. This bench allows for studying fuel pyrolysis under stationary and transient conditions, particularly under supercritical state. The maximum operating parameters are about $1800 \mathrm{~K}, 8 \mathrm{MPa}$ and $0,6 \mathrm{~g} . \mathrm{s}^{-1}$ inside the chemical reactor heated by a furnace. It is notably composed of a Gas Chromatograph and a Mass Spectrometer. Coupling experimental and numerical approaches is hoped to improve knowledge about pyrolysis. The test bench is described in a previous paper (Gascoin et al., 2007). The fuel is the n-dodecane because of its representativity of aeronautic kerosene and of its purity. The purpose of this present work is firstly to give a numerical and experimental validation of the pyrolysis channel. Secondly, some very interesting examples are provided to show the capacities of the code. The simulations are used to furnish information, which are not measured during the experiments.

\section{Governing equations of the full transient model}

RESPIRE considers a complete hypersonic cooled vehicle. It allows for studying under transient conditions, the coupling between the pyrolysis inside the cooling channel and the combustion inside the engine, so as to the thermal consequences on the engine and the thrust of the vehicle. All the governing equations are given in details in previous work (Gascoin 2006). The cooling channel can be studied alone to simulate a chemical reactor. The related equations are written in transient state and the resolving method is a finite differences one. Partial derivative equations are discretized in space (centred scheme) and solved in time (explicit scheme). An average temperature is computed in the wall, considering radiative, convective and conductive heat fluxes.

The fluid is treated as an average single phase flow but possibly multi-species. The velocity of the fluid is determined by the momentum equation and its enthalpy by the energy equation. The effusion through the walls can be investigated thanks to the Darcy Law. RESPIRE could treat several fluid types. The main one is n-dodecane, for which a full mechanism (Dahm et al., 2004) is used (1185 reactions and 153 species, designed by the French laboratory DCPR). The transport equation is solved for each species.

An equation of state is used to determine the density considering the perfect gases law modified by the compressibility factor. The Pitzer acentric factor is used. The LeeKesler tables are needed. The heat capacity is corrected following the temperature and the pressure. Pressure of fluid is determined by use of Bulk Modulus.

\section{Results and discussion}

\subsection{Stationary hydraulic numerical validation of the fluid flow}

The numerical stationary reference data have been obtained with NANCYNETIK, a former "in-house" MBDA code (Daniau et al., 2004). A chemical reactor is considered and is heated by a furnace, whose temperature depends on the position. It is comprised between $1500 \mathrm{~K}$ and $1900 \mathrm{~K}$. The mass flow rate is equal to $0.05 \mathrm{~g} . \mathrm{s}^{-1}$. The fluid is the 
$\mathrm{n}$-dodecane. It is injected at a temperature of $300 \mathrm{~K}$ and at a pressure of $3.5 \mathrm{MPa}$. Such a test case is representative of the experimental COMPARER bench.

If velocity trend are of good agreement in the chemical reactor (Figure 1a), numeric values between the two codes are slightly different. This is attributed to the physical fluid properties calculations. Indeed, data tables in temperature and pressure are used in NANCYNETIK whereas RESPIRE computes these data with the method described above in the section 2. As the fluid temperature given by RESPIRE is lower in the first $0.4 \mathrm{~m}$ (Figure $1 \mathrm{~b}$ ), the density is higher and the resulting fluid velocity for a fixed mass flow rate is lower. Furthermore, as the fluid compressibility is taken into account by RESPIRE and not by NANCYNETIK, it may be possible to observe an accumulation of fluid, particularly in the critical region $(0.2 \mathrm{~m}$ for almost $1 \mathrm{~m}$ of supercritical fluid), near $658 \mathrm{~K}$. This would result in a velocity decrease in this region and in a Reynolds number decrease too. Consequently, the fluid temperature is lower than without accumulation. Furthermore, for the same computed fluid temperature with both numerical codes (around $0.42 \mathrm{~m}, 0.48 \mathrm{~m}$ and $0.52 \mathrm{~m}$ ), the velocity is the same. This highlights the fact that for similar conditions, discrepancies are lower than few percent.

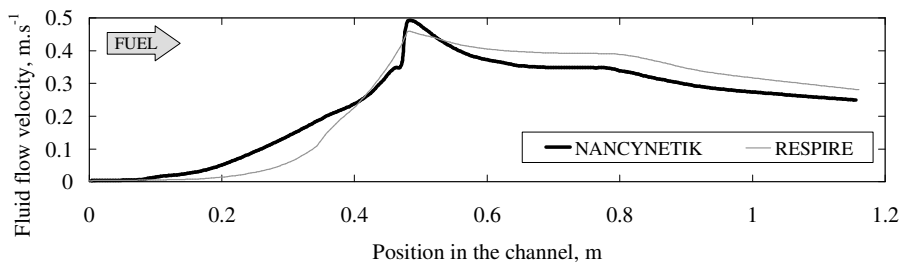

a)

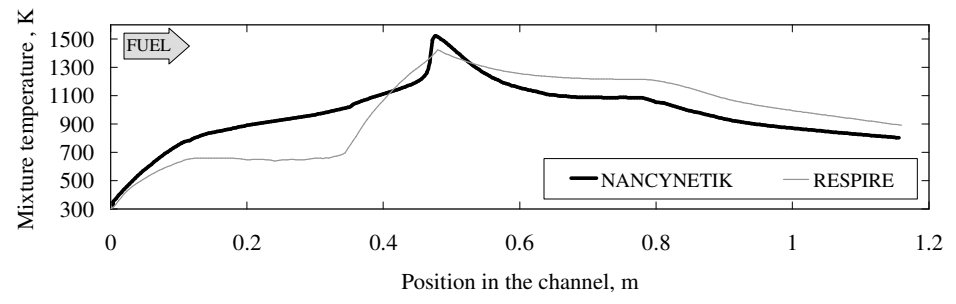

b)

Fig. 1 Velocity (a) and mixture temperature (b) profiles in the cooling channel at equilibrium.

\subsection{Stationary thermal experimental validation of fluid flow}

An experimental test case from MBDA-France and its partners of the Prométhée program is used to validate thermal behaviour of fluid inside the cooling channel. A cylindrical one meter long reactor is heated by its external surface. The fluid temperature is measured at the reactor outlet. For different temperature of the system, the validation is conducted on the outlet fluid temperature, witness of all the thermal aspects involved in the channel. The geometry of the chemical reactor considered numerically is not cylindrical because it is not taken into account by the RESPIRE code. A panel with pin fins is considered with the corresponding empiric correlations for the Prandtl and Nusselt numbers calculation. The internal height and width of the reactor are respectively $5.10^{-3} \mathrm{~m}$ and $8.10^{-3} \mathrm{~m}$; the wall thickness is about $2.5 .10^{-3} \mathrm{~m}$.

The thermal discrepancies (Figure 2) are lower than $10 \%$ between the numerical and experimental data. They are attributed to the geometric configuration because the pin fin geometry corresponds to a gap of $30 \%$ for thermal exchange surface and hydraulic diameter. Nevertheless, results are good enough for the COMPARER project. Furthermore, for such pyrolysis configuration, the thermal radial gradient in the 
cylindrical reactor has been numerically determined to be around $40 \mathrm{~K}$, thanks to the CFD commercial software CFD-ACE. As RESPIRE is a 1-D code, discrepancies remain acceptable. Another calculation has been conducted for the $873 \mathrm{~K}$ external face temperature test case considering a pin fin geometry but with modified hydraulic diameter $\left(5.10^{-3} \mathrm{~m}\right)$ and external exchange surface. The latest is computed for a given computation space step for a cylindrical tube of $9.5 .10^{-3} \mathrm{~m}$ external diameter. This calculation gives an outlet fluid temperature of $774 \mathrm{~K}$ against $690 \mathrm{~K}$ with the previous geometric data. As the pin fin geometry still overestimate the thermal exchange compared to cylinder configuration, the results are consistent and they remain in the 40 $\mathrm{K}$ gradient numerically observed in the 2-D configuration by $\mathrm{CFD}$ approach.

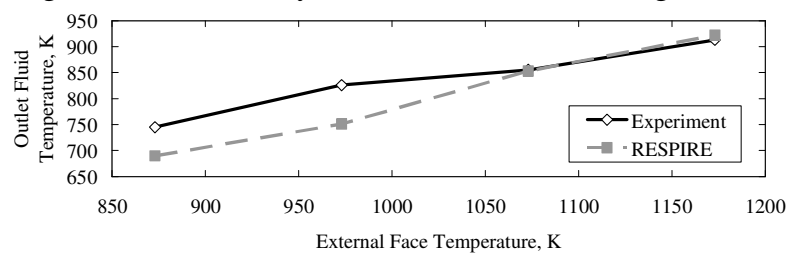

Fig. 2 Comparison of experimental and numerical data for thermal validation.

\subsection{Transient validation on outlet fluid temperature}

An experimental test case from MBDA-France and its partners is used to test transient validity of RESPIRE. A chemical reactor is equipped by thermocouples, located on the upper external face. Along the channel, the fluid (initially hot) is simply subjected to natural cooling with walls, which exchange by convection with external environment. The transient temperatures and pressures are measured at the inlet and outlet of the channel. The injected fluid inside the channel is changing from air to kerosene after $27 \mathrm{~s}$ of experiment and again to air after $70 \mathrm{~s}$. The outlet fluid temperatures are investigated during $160 \mathrm{~s}$ with the two fluids alternatively (Figure 3a). If the trend of calculated data looks like the one of measured data, their values can be $40 \%$ higher.
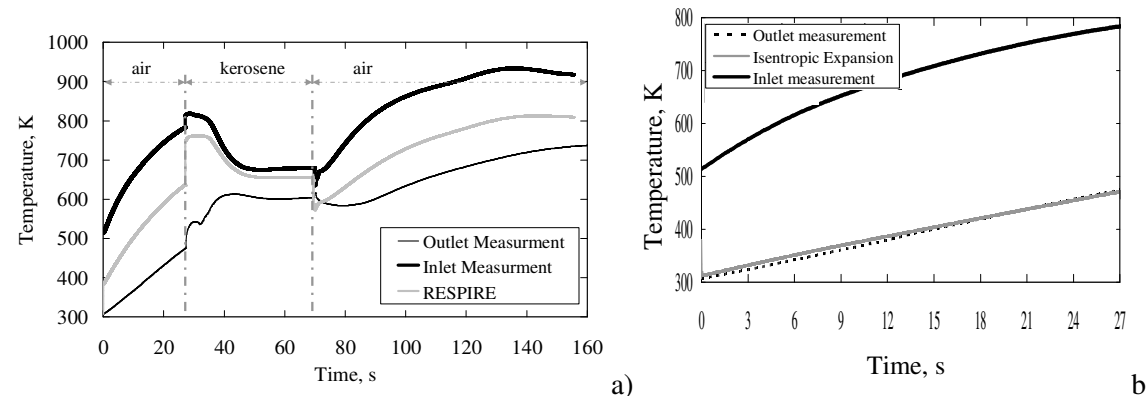

Fig. 3 Outlet fluid temperatures for transient calculations and experimental measurements (a) and Effect of an isentropic relaxation on numerical calculation (b).

This result is attributed to the pressure variations, which have been experimentally measured at the entrance. The pressure is typically measured to be equal to $1.5 \mathrm{MPa}$ in entrance and $0.16 \mathrm{MPa}$ at the outlet. This cannot be due to regular pressure loss over a so small panel of few centimeters. Inlet temperature and pressure measures are taken just before a singular pressure loss. Consequently, an expansion of the fluid appears and modifies the fluid temperature. An isentropic expansion is chosen at the panel entrance from measured inlet pressure (roughly $1.5 \mathrm{MPa}$ ) to $0.25 \mathrm{MPa}$; even if a polytropic 
expansion should be more realistic. Then, with an inlet pressure of about $0.25 \mathrm{MPa}$, the regular pressure loss inside the channel conduct to furnish an outlet pressure of roughly $0.16 \mathrm{MPa}$, which has been experimentally measured. The figure $3 \mathrm{~b}$ shows the good agreement between calculated and measured data with discrepancies lower than $10 \mathrm{~K}$.

\subsection{Experimental validation of pyrolysis}

The COMPARER bench has successfully furnished a detailed comprehension of pyrolysis phenomena (Gascoin et al. 2007). The n-dodecane has been studied (Gascoin 2006) on a wide range of parameters $(700 \mathrm{~K}$ to $1100 \mathrm{~K}, 10$ bars to $50 \mathrm{bars}$, residence time from $20 \mathrm{~s}$ to $100 \mathrm{~s}$ ). These data allow to test RESPIRE to verify its validity.

On a first example for extreme temperature and pressure conditions (Figure 4a), the mole fractions of gases at ambient conditions are measured experimentally and compared to numerical results. The lack of hydrogen obtained with the experiments is attributed to its high diffusivity, which makes it difficult to measure. The code shows here a first interest because it enables to consider hydrogen in a better way. The other discrepancies are due to measurement uncertainties on the temperature. For a $20 \mathrm{~K}$ thermal gradient, the pyrolysis rate can vary by $10 \%$, which explains the observed differences. Indeed, the fluid temperature cannot be measured inside the process but only in the furnace, outside the chemical reactor.

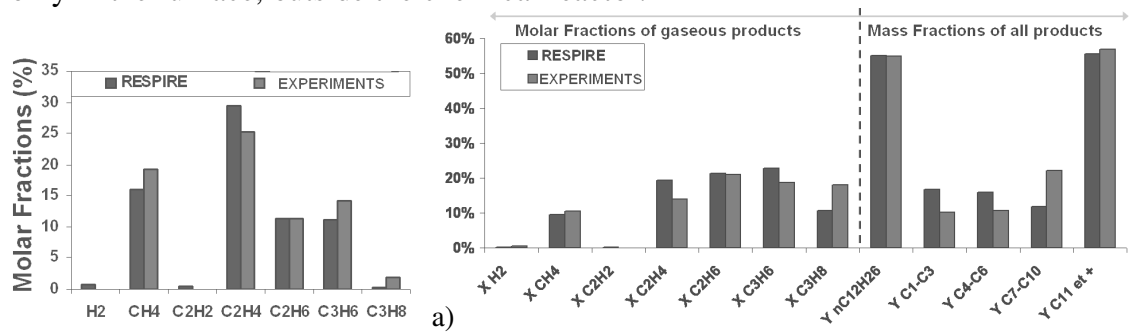

Fig. 4 (a) Composition of gaseous products obtained for a pyrolysis at $1100 \mathrm{~K}, 10$ bars, 0,05 g.s ${ }^{-1}$. (b) Composition of pyrolysed products obtained at $773 \mathrm{~K}, 50 \mathrm{bars}, 0,05 \mathrm{~g} . \mathrm{s}^{-1}$.

For moderate temperature and pressure conditions (Figure $4 \mathrm{~b}$ ), the mole and mass fractions of gases and liquids are observed. The discrepancies are, in these conditions, due to 2-D effects (hydraulic and thermal ones) in the reactor. Indeed, RESPIRE considers one phase whereas two phases can appear depending on operating conditions. Thus, a gliding can be observed at the reactor outlet. Due to high residence time between the process and the analysis, this conducts to some experimental uncertainties. For low pyrolysis rate, RESPIRE also shows a good agreement with experiments. The differences on composition (some percents) are acceptable for the COMPARER project because it is preferred to take all the system with detailed chemistry into account with a moderate accuracy rather than a simplified configuration with higher accuracy.

\subsection{Some interesting use of RESPIRE}

After validation, RESPIRE has been used to provide additional information on the experiments. For example, it gave firstly a justification of using the maximum temperature measured in the furnace, outside the chemical reactor, to characterize the thermal conditions of the pyrolysis. Indeed, the maximum temperature reached by the fluid is closed to the maximum one measured in the process (Figure 5a). A cooling of the fluid has been shown in the last third of the reactor thanks to the code. In addition, it is proved that no chemical reaction appear during this cooling and after the reactor outlet. Consequently, the chemical composition depends on the maximum temperature reached by the fluid, which directly depends on the one of the process. Furthermore, 
RESPIRE allows studying the residence time in the process and it appears that three different times are observed. The first one $(75 \mathrm{~s})$ is dedicated to the heating of the fluid (until $800 \mathrm{~K}$ ) during which no pyrolysis appears (Figure 5b). Then, a short period (10 s) corresponds to the pyrolysis (from $800 \mathrm{~K}$ and above) whereas the cooling of the fluid takes place during the last $15 \mathrm{~s}$. Finally, only $10 \%$ of the global residence time is allocated to the fuel pyrolysis. This parameter is not accessible experimentally.
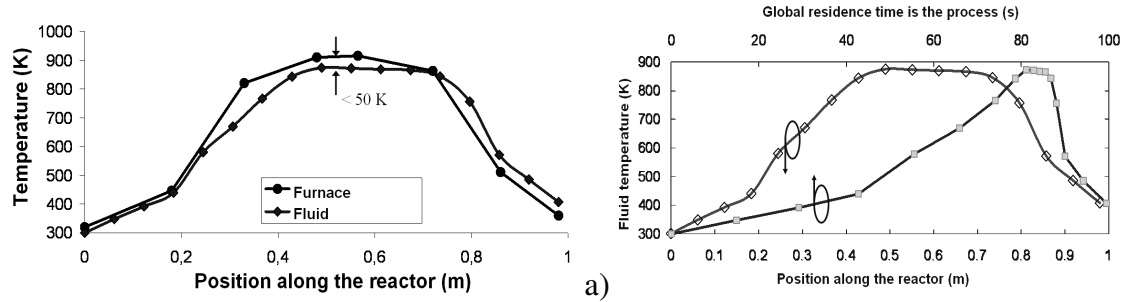

a)

b)

Fig. 5 (a) Fluid temperature computed in the reactor of the given experimental thermal profile. (b) Fluid temperature computed in the reactor and given as a function of time and position.

\section{Conclusion}

The COMPARER project studies the active cooling of a scramjet for hypersonic flight application. It is needed to have at our disposal a numerical tool able to take into account all the phenomena involved in this technology with a low computational cost. A one-dimensional transient model, called RESPIRE, has thus been developed. A complete pyrolysis mechanism (1185 reactions and 153 species) has been implemented. The hydraulic and thermal behaviour of the code is confirmed to be good enough for the project. The transient validation has shown a good agreement of RESPIRE despite the complexity of study cases, with alternative and sudden changes in fluid nature. A validation of the chemistry has been realized with the dedicated experimental bench. The differences have been understood and remain acceptable for this project.

Some examples have been presented in this paper to show the interest of RESPIRE to deeply investigate the experimental results, particularly for the fluid temperature and the residence time inside the process. RESPIRE continues to be systematically used on the experimental test cases to give additional information about unknown parameters. Presently, RESPIRE is used to investigate the relationship between the pyrolysis of the fuel and the quantity of product gases obtained at ambient conditions.

\section{Acknowledgements}

The present work was realised thanks to the "Conseil Général du Cher", of the "Conseil Régional du Centre", of the FRED, of the FEDER, of the FSE, of MBDA-France.

\section{References}

Dahm K.D. et al., 2004, Experimental and Modelling Investigation of the Thermal Decomposition of n-Dodecane, J. Anal. Appl. Pyrol., 71, pp. 865-881.

Daniau E., Bouchez M., Gascoin N., 2004, SCRAMJET Active Cooling Analysis Using ndodecane as a Generic Endothermic Fuel, TPPA, St Petersburg, Russia, 12-14 July.

Gascoin N., 2006, Etude et mesure de paramètres pertinents dans un écoulement réactif, PhD Thesis, Orleans University, 30/11/06, Bourges.

Gascoin N. et al., 2007,"Pyrolysis of Supercritical Endothermic Fuel: Evaluation for Active Cooling Instrumentation.", Récents Progrès en Génie des Procédés, N96, Ed. Lavoisier.

Powell O.A. et al., 2001, Development of Hydrocarbon-Fueled Scramjet Engines: The Hypersonic Technology (Hytech) Program, J. Prop. Power, Vol. 17, No. 6, Nov-Dec. 